\title{
Endometrial cancer with implantation metastasis to vagina: a case report
}

\author{
Muhammad Eimaduddin Sapiee ${ }^{1 *}$, Wan Rosmidah Wan Abas ${ }^{1}$, Roziana Ramli ${ }^{1}$, \\ Muhd Afif Mohd Yusof ${ }^{2}$, Ahmad Fazlin Nasaruddin²
}

\begin{abstract}
${ }^{1}$ Department of Obstetrics and Gynecology, Hospital Sultanah Nur Zahirah, Kuala Terengganu, Terengganu, Malaysia ${ }^{2}$ Department of Pathology, Hospital Sultanah Nur Zahirah, Kuala Terengganu, Terengganu, Malaysia
\end{abstract}

Received: 03 January 2020

Revised: 31 January 2020

Accepted: 05 February 2020

\section{*Correspondence:}

Dr. Muhammad Eimaduddin Sapiee,

E-mail: eimad0307@gmail.com

Copyright: ( the author(s), publisher and licensee Medip Academy. This is an open-access article distributed under the terms of the Creative Commons Attribution Non-Commercial License, which permits unrestricted non-commercial use, distribution, and reproduction in any medium, provided the original work is properly cited.

\begin{abstract}
Authors present a case of vaginal implantation metastasis following a diagnosis of endometrial cancer. A 58-year-old lady presented with postmenopausal bleeding and was later diagnosed to have endometrial cancer. She underwent an extra-fascial hysterectomy and bilateral salpingo-oophrorectomy with pelvic lymphadenectomy for Stage 3A endometrioid adenocarcinoma of the endometrium. The lymph nodes and cervix were free from the disease and no lymphovascular invasion was seen on the pathological specimen. She defaulted adjuvant radiotherapy and was lost to follow up. Six months later she had a tumour recurrence at the vaginal introitus just below the urethral orifice and awal from the vaginal vault with similar histopathological findings as previous cancer. This case highlights the rare occurrence of implantation metastasis of endometrial cancer.
\end{abstract}

Keywords: Endometrial cancer, Endometrioid carcinoma, Vaginal implantation metastasis

\section{INTRODUCTION}

Endometrial cancer is one of the most common malignancies of the female reproductive system. In the United States, more than 60,000 new cases are diagnosed each year and this diagnosis is responsible for more than 10,000 deaths annually. ${ }^{1}$ In Malaysia, endometrial cancer is the seventh most common cancer in female with a lifetime risk of 1 in $224 .^{2}$ Endometrial cancer spreads normally via local invasion as illustrated in the FIGO staging. Occasionally it spreads regionally to the lymph nodes and sometimes hematogenously or via lymphatic drainage to other organs. Typical metastatic sites include the pelvis, pelvic nodes, peritoneum, liver and lungs but sometimes atypical metastasis occur e.g. to extra abdominal lymph nodes, adrenals, brain and bones. ${ }^{3}$ Very rarely it spreads by metastatic implantation. Here we report a rare atypical site of metastasis i.e.: implantation metastasis to the sub-urethral area of the vagina introitus.

\section{CASE REPORT}

A 58-year-old para 5, post-menopause for 5 years was first seen in the gynaecology clinic, Hospital Sultanah Nur Zahirah (Kuala Terengganu, Malaysia) following episodic post-menopausal bleeding since 3 years prior. Clinical assessment including abdominal examination was essentially unremarkable. Vaginal examination revealed a normal and healthy cervix and vagina. Sonographic assessment showed a bulky uterus with a 3 $\times 3 \mathrm{~cm}$ intra-uterine mass.

Endometrial biopsy revealed moderately differentiated endometroid adenocarcinoma (Figure 1,2). 
The patient underwent extra-fascial hysterectomy and bilateral salpingo-oophrorectomy with pelvic lymphadenectomy. The intra-uterine tumour was found to have invaded more than half of myometrium until serosal layer. There was no involvement of the lymph nodes, cervix, paracervical or parametrial region. The cancer was staged as 'Stage 3A Endometriod Adenocarcinoma of the Endometrium, FIGO grade 2 with no lymphovascular invasion'.

Post-operative recovery was good and the patient was counselled for adjuvant radiotherapy at an oncology centre in another state. However, she defaulted the appointment for radiation therapy and was lost to our follow up schedule. After 6 months, the patient was seen again complaining of per-vaginal bleeding. Examination revealed a cauliflower growth with contact bleeding at the anterior vagina below urethra involving the vaginal interoitus measuring around $3 \times 3 \mathrm{~cm}$ (Figure 3,4). The rest of the entire length of the vagina until the vaginal vault were otherwise normal and free of any growth. Biopsy of the vaginal mass disclosed adenocarcinoma. Unfortunately, despite extensive counselling, she refused further intervention.

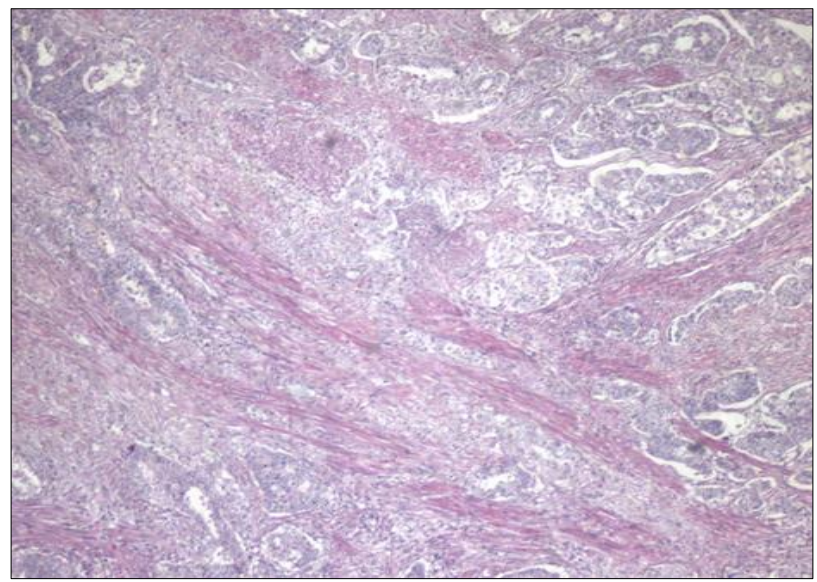

Figure 1: Malignant cells arranged in sheets.

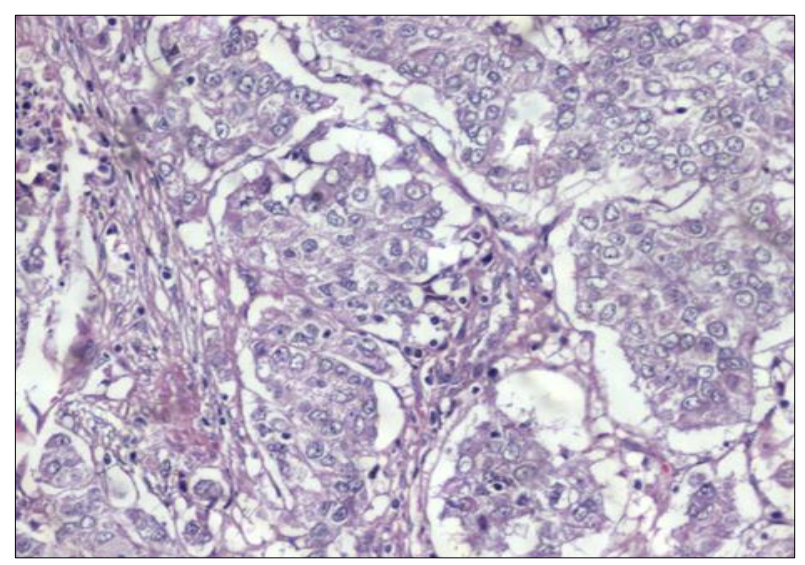

Figure 2: The malignant cells are markedly pleomorphic with vesicular nuclei and occasional prominent nucleoli.

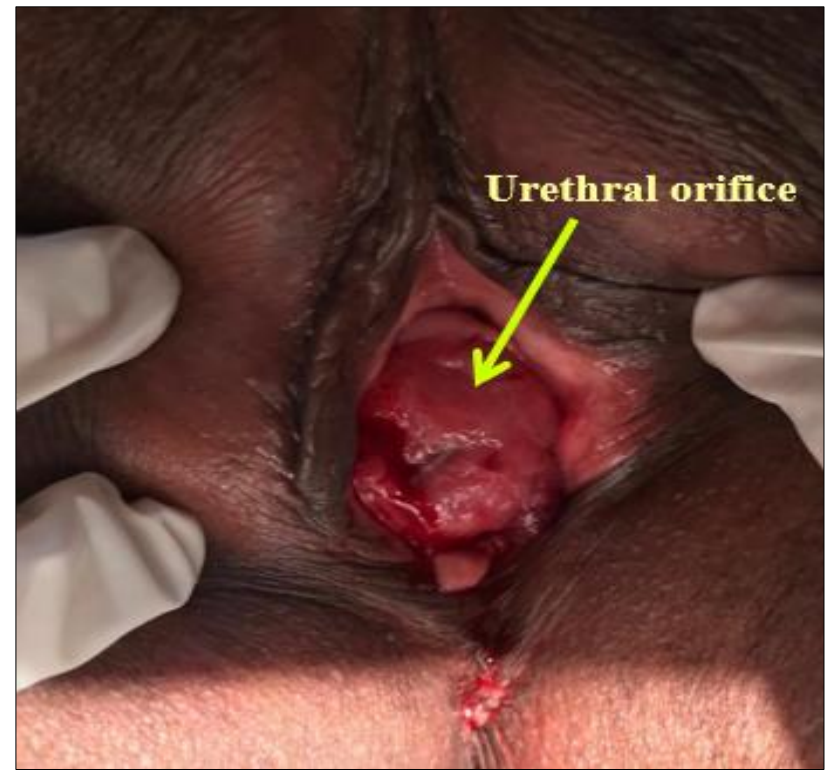

Figure 3: Growth at the vaginal introitus with contact bleeding just beneath the urethral orifice.

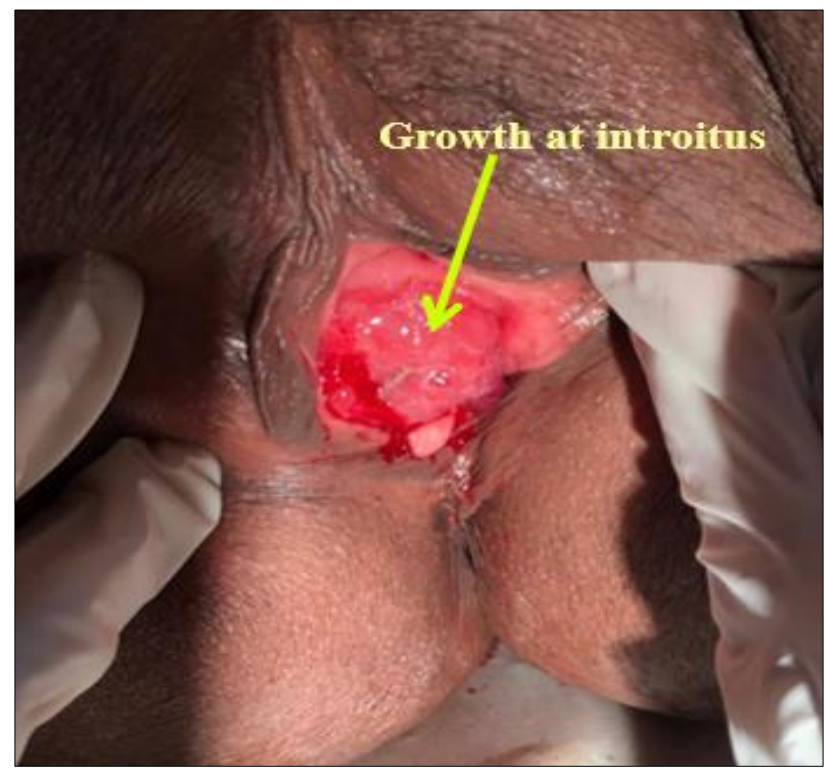

Figure 4: Cauliflower growth at the sub urethral area of vaginal introitus measuring $3 \times 3 \mathrm{~cm}$.

\section{DISCUSSION}

Endometrial cancer is one of the most common gynaecological cancer. The increasing incidence of this cancer over the years has been attributed by many factors including increasing prevalence of diabetes and obesity. The most common histological subtype is endometrioid adenocarcinoma and patients are often diagnosed early stage when the disease is still confined to the uterus. This is not the case with this patient as she was diagnosed at stage $3 \mathrm{~A}$. It is very unfortunate that although her bleeding symptom started many years before, treatment was only sought just recently. 
Her final diagnosis was stage $3 \mathrm{~A}$ endometriod adenocarcinoma FIGO grade 2 with no lymphovascular invasion. The lymph nodes were all negative. She defaulted radiation therapy and her treatment was therefore incomplete. One would then expect her to have a recurrence soon enough, and she did. But it was at an unexpected site. Most frequent recurrent endometrial cancer occurs as local invasion within 2 or 3 years from surgery. ${ }^{4}$ Metastasis to distant organs usually occur via lymphatics and hematogenous route to liver, lungs etc. The recurrence of cancer in her case was in fact at the sub urethral area of the vagina introitus, which was further away from the common recurrence at the vaginal vault. This is unexpected because the most common location of recurrence within the vagina is the apex and middle vaginal canal, followed by the distal vagina, and lastly the sub urethral area. ${ }^{5}$

We believe this is a case of an implantation metastasis. Implantation metastasis is an interesting condition. It signifies the ability for the desquamated cancer cells to grow in any parts of the body they come into contact with. Implantation metastasis is often iatrogenic. The example of implantation or inoculation metastasis is needle-track metastasis following biopsy procedure of a primary cancer. Avoiding and reducing iatrogenic dissemination of cancer cells is an important principle for the management of this kind of cancer.

Implantation metastasis normally have a direct correlation between the procedures and the site of metastasis e.g., skin implantation metastasis of ovarian cancer after paracentesis and perineal implantation metastasis after prostate biopsies. In this case however, what could be the possible mechanism?

This literature search found 2 other cases of vaginal implantation metastasis from endometrial cancer. Wang $\mathrm{Y}$ et al, believed that their case resulted from the shedding of cancer cells during examination or surgery. ${ }^{6}$ Hisamoto $\mathrm{K}$ et al, believed that the vaginal lesion in their case have been implanted through trans-vaginal uterine removal during the laparoscopic surgery. ${ }^{7}$ This case probably also resulted from shedding of cancer cells during examination or surgery.

The reason why the cancer cells have a certain affinity to be implanted in a certain particular site is unknown. To begin with, there are too few in vivo and in vitro studies to comment definitively even on the viability of the disseminated endometrial cells. ${ }^{8}$ Few hypotheses were suggested including one that suggests areas which has damaged epithelial lining secondary to examination, procedures or surgery are prone to develop implantation metastasis. ${ }^{9}$ Some authors advocate cervical cerclage, ligation of the fallopian tubes and vaginal douching to prevent carcinoma cells from implanting in other organs. ${ }^{6}$ Reducing unnecessary gynaecological examinations is expected to lower the possibility of cancer cell dissemination. ${ }^{8}$ Further research should be carried out to establish the actual mechanisms of vaginal implantation metastasis of cases of endometrial carcinoma. In the meantime, certain measures e.g., vaginal douching, cervical cerclage prior to surgery, reducing unnecessary vaginal examinations etc., are all attractive possible preventive measures.

Funding: No funding sources

Conflict of interest: None declared

Ethical approval: Not required

\section{REFERENCES}

1. Siegel RL, Miller KD, Jemal A. Cancer Statistics, 2016. CA Cancer J Clin. 2016;66:7.

2. National Cancer Registry. Malaysian National Cancer Registry Report 2007-2011, 2016. Available at: https://www.crc.gov.my/wp-content/uploads/ documents/report/MNCRRrepor2007-2011.pdf. Accessed on $2^{\text {nd }}$ January 2020.

3. Sears JD, Greven KM, Hoen HM, Randall ME. Prognostic factors and treatment outcome for patients with locally recurrent endometrial cancer. Cancer. 1994;74:1303-8.

4. Tejerizo-Garcia A, Alvarez-Conejo C, MunozHernando L, Guillen-Gamez C. Tumor recurrence and tumor-related mortality in endometrial cancer: Analysis in 276 patients. Indian J Cancer. 2015;52(4):682-4.

5. Kurra V, Krajewski KM, Jagannathan J, Giardino A, Berlin S, Ramaiya N. Typical and atypical metastatic sites of recurrent endometrial carcinoma. Cancer Imaging. 2013;13(1):113.

6. Wang Y, Du J, Lv S, Sui Y, Xue X, Sun C, et al. Vaginal implantation metastasis of endometrial carcinoma: a case report. Oncol Letters. 2016;12(1):513-5.

7. Hisamoto K, Kitai M, Otoshi A, Tsukahara C, Nishio Y, Miyatake T. Vaginal mucosal implantation after total laparoscopic hysterectomy for an early stage endometrial cancer. Clin Gynecol Obstet. 2018;7(2):5761.

8. Atallah D, el Kassis N, Lutfallah F, Safi J, Salameh C, Nadiri $\mathrm{S}$, et al. Cutaneous metastasis in endometrial cancer: once in a blue moon. World J Surg Oncol. 2014;12:86.

9. Guralp O, Kushner DM. Iatrogenic transtubal spill of endometrial cancer: risk or myth. Arch Gynecol Obstet. 2011;284:1209-21.

Cite this article as: Muhammad Eimaduddin S, Wan Rosmidah WA, Roziana R, Muhd Afif MY, Ahmad Fazlin N. Endometrial cancer with implantation metastasis to vagina: a case report. Int J Reprod Contracept Obstet Gynecol 2020;9:1303-5. 